\title{
Descrição dos Ovos e dos Estádios Ninfais de Triatoma jurbergi Carcavallo, Galvão \& Lent, 1998 Vistos Através de Microscopia Óptica e Eletrônica de Varredura (Hemiptera, Reduviidae)
}

\author{
José Jurberg ${ }^{++}$, Maria Beatriz Araújo Silva, Cleber Galvão, Dayse da Silva Rocha, \\ Helene Santos Barbosa*, Rodolfo U Carcavallo
}

\author{
Laboratório Nacional e Internacional de Referência em Taxonomia de Triatomíneos, Departamento de Entomologia \\ *Laboratório de Ultra-estrutura Celular, Departamento de Ultra-estrutura e Biologia Celular, Instituto Oswaldo Cruz-Fiocruz, \\ Av. Brasil 4365, 21045-900 Rio de Janeiro, RJ, Brasil
}

\begin{abstract}
Description of Eggs and Nymphs of Triatoma jurbergi Carcavallo, Galvão \& Lent, 1998 Through Optical and Scanning Electron Microscopy - Eggs and nymphs of Triatoma jurbergi were described using optical microscopy and scanning electron microscopy. T. jurbergi is a wild species, found in State of Mato Grosso $\left(15^{\circ} S\right.$ and 300 m.a.s.l), Brazil. Eggs showed the operculum and surface with pentagonal and hexagonal cells, with small fractures and punctuations randomly distributed. Differences were found in the five nymphal stages of T. jurbergi, that allow their to be distinguished from the similar species $\mathrm{T}$. guazu. The diagnostic characters most useful for differentiation were the general color of the insect, abdomen shape and its length.
\end{abstract}

Key words: Triatoma jurbergi - nymphs - external morphology - Chagas disease - vectors

Triatoma jurbergi Carcavallo, Galvão \& Lent 1998, é uma espécie afim de T. guazu e foi descrita a partir de espécimes enviados pela Fundação Nacional de Saúde (Funasa), provenientes da localidade de Rondonópolis, a cerca de $280 \mathrm{~km}$ de Barra do Garças, Mato Grosso, Brasil (Carcavallo et al. 1998). Apesar de apresentar hábitos silvestres, T. jurbergi tem sido encontrado nos arredores de habitações rurais e algumas ninfas já foram encontradas no domicílio, no município de Alto Garças, Mato Grosso (Fig. 1), localizado no Alto Araguaia, a $700 \mathrm{~m}$ de altitude e distante $310 \mathrm{~km}$ da capital (16 43'10"S 5337'30"). Esta região apresenta clima quente e úmido, com temperatura média anual de $22^{\circ} \mathrm{C}$ e o T. jurbergi tem sido frequientemente encontrado em ambiente silvestre caracterizado por grandes paredões rochosos abundantemente nidificados (Fig. 2). A relevância desta espécie na epidemiologia da doença de Chagas, ainda não foi estabelecida, embora, a infecção pelo T. cruzi tenha sido obtida em laboratório com a cepa Y CT-IOC 106, mantida na Coleção de Tripanosomatídeos do Instituto Oswaldo Cruz (Ziccardi 1999, comunicação pessoal). Recentemente, Lorosa et al. (2001) encontraram exemplares de $T$. jurbergi naturalmente infectados pelo T. cruzi. Alguns aspectos do ciclo biológico desta espécie foram observados em laboratório por Silva et al. $(1998,1999)$.

Com auxílio do CNPq, do convênio Funasa/Fiocruz no 123/97 e da Faperj

+Autor de contato. Fax: + 55-21-2573.4468.

E-mail:jjurberg@ioc.fiocruz.br

Recebido em 16 abril de 2001

Aceito em 5 de novembro de 2001
A morfologia dos ovos e ninfas de triatomíneos tem sido alvo de estudos de diversos autores (Carcavallo et al. 1975, 1978, Jiménez \& Fuentes 1981, Gonçalves et al. 1985, Jurberg et al. 1986, 1990, 1991, 1998, Mascarenhas 1987, Costa et al. 1991, Jurberg \& Vogel 1994, Jurberg \& Campos 1995, Rocha et al. 1996, Galíndez-Giron et al. 1998, Silva et al. 2000). Estes estudos são importantes na busca de novos parâmetros a serem utilizados na taxonomia dos triatomíneos, tornando-se elementos importantes na elaboração de uma chave dicotômica, auxiliando na determinação do papel de cada espécie vetora, bem como ampliando o conceito específico.

\section{MATERIAIS E MÉTODOS}

Insetos - Os triatomíneos utilizados são oriundos de colônias aclimatadas no Insetário do Laboratório Nacional e Internacional de Referência em Taxonomia de Triatomíneos do Departamento de Entomologia do Instituto Oswaldo Cruz. Todo material encontra-se depositado na Coleção Herman Lent do Instituto Oswaldo Cruz. Ovos: $2979 ; 2980 ; 2981 ; 2982 ; 2983 ; 2984 ; 2985$. Ninfas- $1^{\underline{o}}$ estádio: 2974; 2975; 2976; 2977; 2978. 2o estádio: 2966 ; 2967; 2968; 2969; 2970; 2971; 2972; 2973. 3- estádio: 2961; 2962; 2963; 2964; 2965 . $4^{\circ}$ estádio: 2956; 2957; 2958; 2959; 2960. $5^{\circ}$ estádio: 2950; 2951; 2952; 2953; 2954; 2955.

Microscopia óptica (MO) - Foram observados dez ovos e dez ninfas de cada estádio. O opérculo foi destacado dos ovos e montado entre lâmina e lamínula com fenol, enquanto as ninfas, após as observações dos aspectos cromáticos, foram aquecidas em solução de hidróxido de potássio $(\mathrm{KOH})$ a $10 \%$. As ninfas e os ovos foram desenhados com o auxílio de uma câmara clara acoplada a um microscópio estereoscópico WILD M5.

Microscopia eletrônica de varredura (MEV) - Para análise ultra-estrutural, ovos e ninfas foram escolhidos respectivamente após a postura e a eclosão, posterior- 

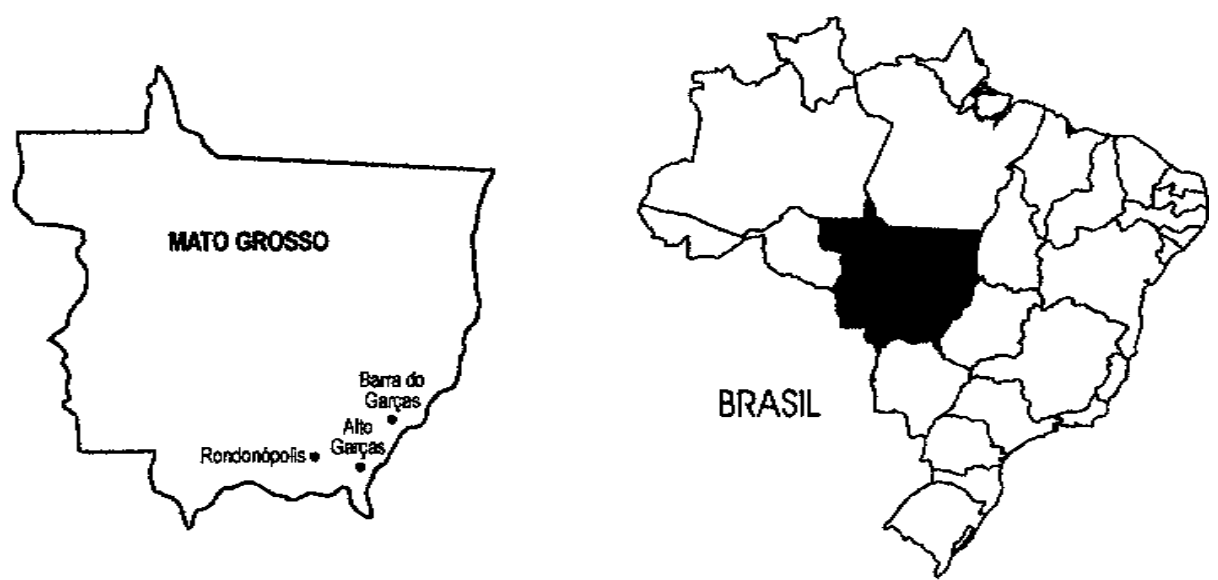

Fig. 1: mapa do Estado do Mato Grosso, Brasil

mente montados em suportes metálicos com $1,2 \mathrm{~cm}$ de diâmetro, fixados com fita dupla face e metalizados com ouro. O material foi observado em microscópio eletrônico de varredura, Zeiss, modelo DSM 940. As imagens foram fotografadas com filme Neopan SS 120 Fugi e/ou capturadas digitalmente utilizando-se o programa DIT (Digital Image Transfer) para um computador compatível IBM-PC

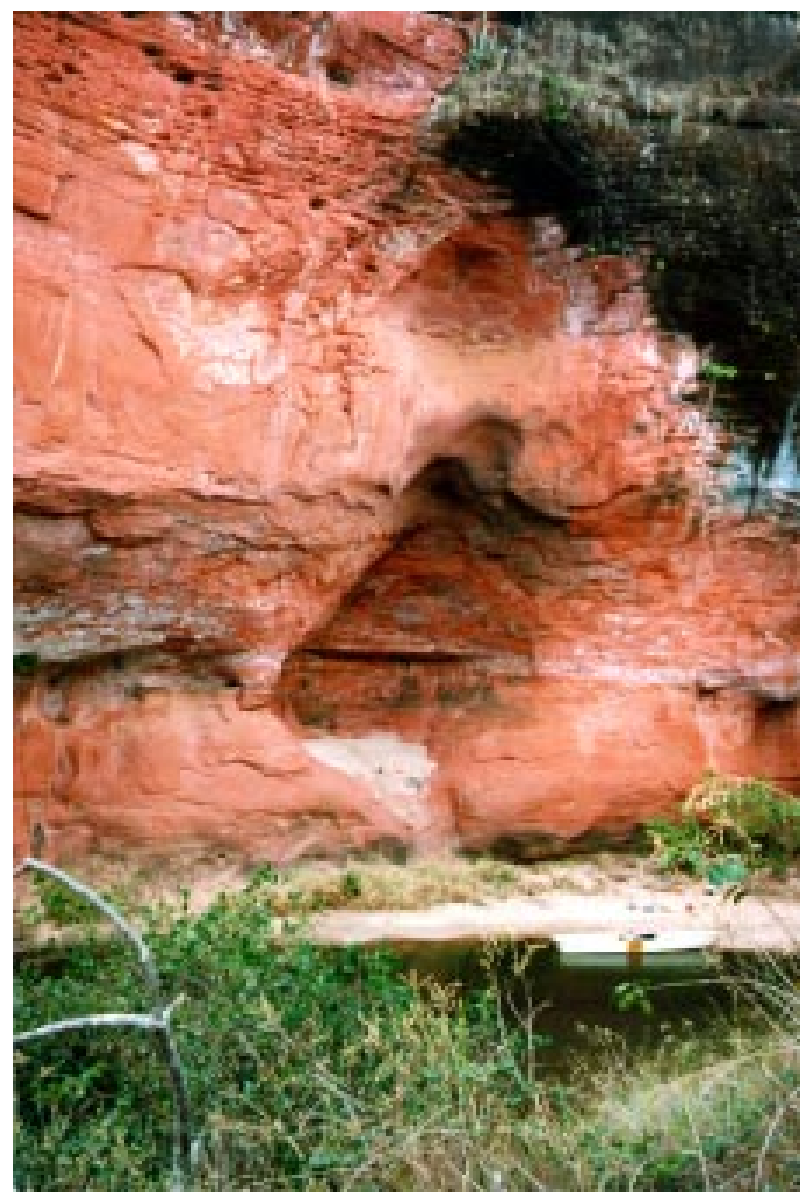

Fig. 2: vista parcial do habitat silvestre de Triatoma jurbergi Carcavallo, Galvão \& Lent, 1998. Município de Alto Garças, Mato Grosso, Brasil e processadas com o programa Adobe Photo Shop 5.0.

As sensilas foram identificadas de acordo com McIver (1975), Zacharuk (1980), McIver e Siemicki (1984, 1985), Catalá e Schofield (1994), Catalá (1997a,b) e Da Rosa et al. (1999).

\section{RESULTADOS}

Descrição dos ovos

Os ovos apresentam coloração esbranquiçada imediatamente após a postura, até atingirem coloração avermelhada no período da eclosão. A relação entre o diâmetro do opérculo e a largura máxima é de 1:1,8. Comprimento total médio de 2,27 $\pm 0,02 \mathrm{~mm}$. Em MO, corpo e opérculo apresentam o exocório ornamentado com células poligonais, justapostas, sendo as do opérculo em sua maioria hexagonais, com algumas pentagonais, contendo, pequenas fraturas. Corpo constituído por áreas hexagonais e pentagonais contendo além de pequenas fraturas, pontuações distribuídas aleatoriamente em toda a sua extensão (Fig. 3), melhor visualizadas por MEV (Fig. 4a e 4b).

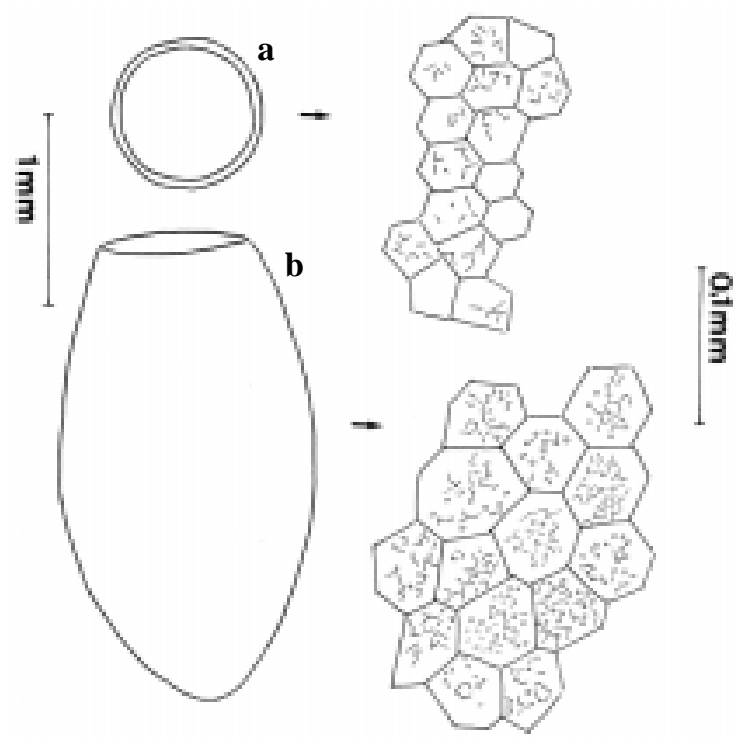

Fig. 3: Triatoma jurbergi Carcavallo, Galvão \& Lent, 1998. Desenho do ovo - a: opérculo; b: corpo 

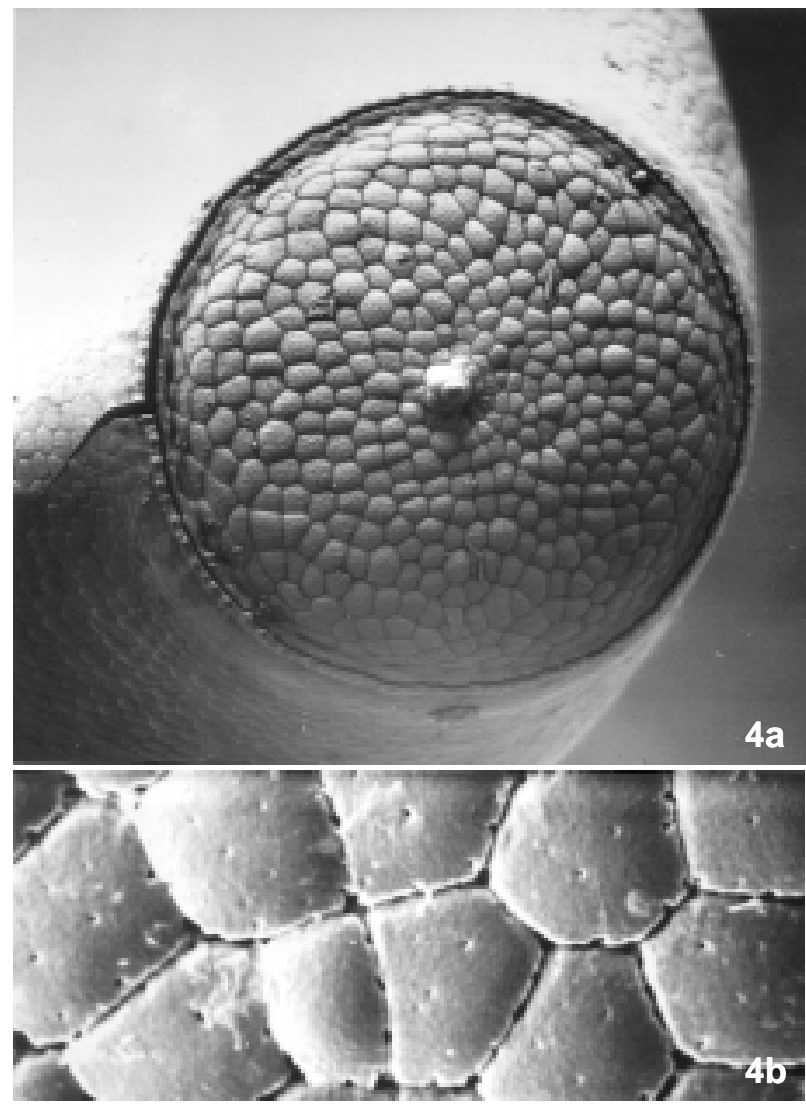

Fig. 4a, b: ultra-estrutura do ovo de Triatoma jurbergi, em destaque o opérculo e a sua superfície, com células pentagonais e hexagonais apresentando perfurações distribuídas irregularmente (120X; 1000X)

\section{Descrição das ninfas}

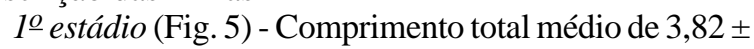
$0,068 \mathrm{~mm}$. Coloração castanho-avermelhada, apresentando na cabeça inúmeras cerdas implantadas em tubérculos setíferos, distribuídos irregularmente. Pronoto glabro com 1+1 tubérculos setíferos na área central, mesonoto com alguns tubérculos na área central e região do metanoto com 1+1 tubérculos na área central. Abdome alongado; urotergitos apresentam 1+1 fileira retilínea de tubérculos, que lhes confere um aspecto de linhas paralelas.

A cabeça em vista dorsal possui o tegumento com aspecto irregular devido à presença de tubérculos setíferos na região anteocular e pós-ocular. Esta irregularidade é mais evidente nos bordos laterais, principalmente nas regiões que vão do bordo anterior do olho até o bordo do tubérculo antenífero e do bordo posterior do olho até o início do pescoço. Nesta área, os bordos são abaulados, enquanto na região anteocular, são paralelos. Jugas de ápice arredondado são observadas atingindo o nível mediano do $1 \underline{\text { o}}$ segmento antenal. Sulco pós-ocular bem demarcado. Olhos compostos de coloração negra constituídos por omatídeos circulares afastados uns dos outros, contendo uma área póstero-inferior lisa, sem omatídeos. Entre a largura da região pós-ocular e a da região anteocular a proporção média é de 1:2,8; entre a largura da região ocular e a da região interocular a proporção é de

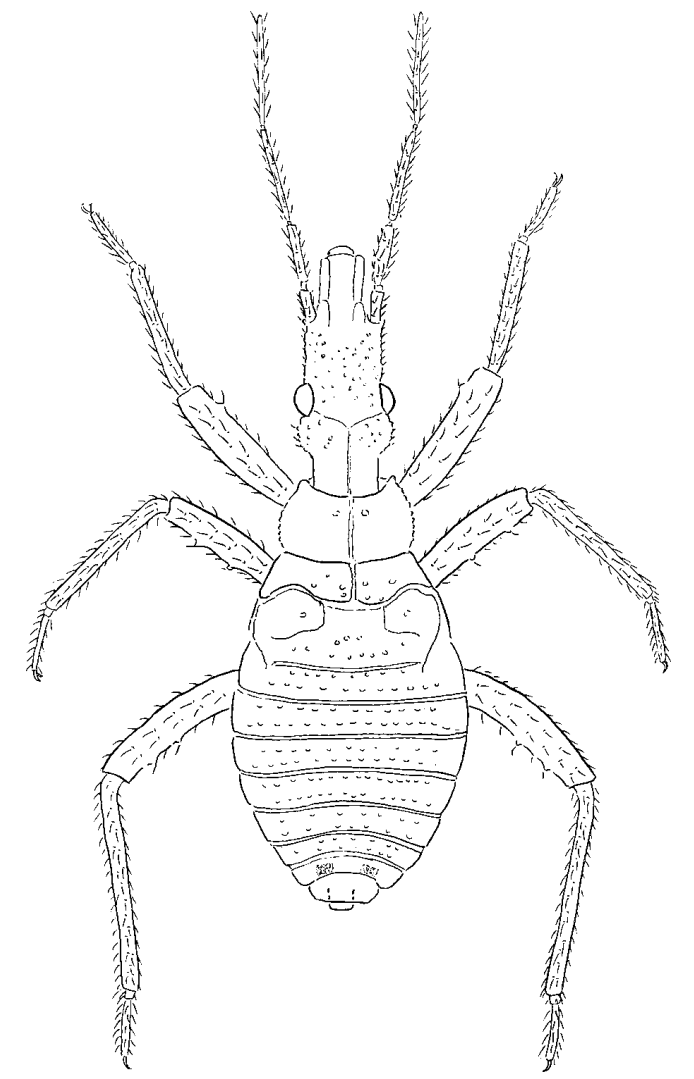

Fig. 5: Triatoma jurbergi Carcavallo, Galvão \& Lent, 1998 - Ninfa de 1 o estádio, vista dorsal

1:0,7. Antenas inseridas em tubérculos laterais localizados no limite do terço anterior da cabeça, apresentando, lateralmente, uma protuberância com uma cerda implantada em seu ápice. Coloração negra observada no $1^{\underline{0}}$ segmento, na porção terminal do $2^{\underline{0}}$, e em todo o $3 \underline{0}$; estes segmentos são recobertos de cerdas com maior densidade, tendo o 4응 segmento cerdas maiores e espaçadas. Os artículos antenais apresentam as seguintes proporções médias: 1:2,1:2,9: 3,5. Rostro retilíneo com o 3 o segmento atingindo o bordo anterior do proesterno quando em repouso e de coloração menos intensa que a cabeça. Proporções médias entre os segmentos: 1:2,7: 2,1. Tórax de coloração marrom escuro, dorsalmente ornamentado por poucas cerdas implantadas em tubérculos circulares distribuídas de forma aleatória pelo tegumento granuloso. Pronoto de forma trapezoidal, exibindo o colar com ângulos ântero-laterais e 4 tubérculos localizados nos bordos laterais. Tubérculos discais visíveis, dorsalmente dividido em duas partes iguais por uma linha mediana longitudinal de coloração mais clara. Mesonoto formado por $1+1$ placas retangulares, com 1+1 reentrâncias no bordo inferior, com tegumento granuloso, contendo pêlos na região mediana, divididos por uma faixa membranosa dorsal. Bordo externo recortado por três projeções espiniformes com uma cerda grossa em cada ápice. Metanoto de coloração escura, formado por $1+1$ placas retangulares de bordos internos retos, bordos superior e inferior divergentes, bordos externos arredondados e recortados com 
pequenas cerdas em seu contorno. Pernas apresentando coxas, trocânteres, articulações entre fêmures e tíbias com a porção mediana basal dos fêmures mais claras que as tíbias e os tarsos, contendo 1+1 tubérculos setíferos na região subapical superior do fêmur das pernas metatorácicas e $2+2$ tubérculos na região subapical inferior dos fêmures das pernas meso e metatorácicas. Abdome de coloração castanho avermelhado claro, com marcação nítida formando 9 segmentos, separados por uma membrana dupla do $1^{\mathrm{o}}$ ao $8^{\mathrm{o}} \underline{\mathrm{o}}$ segmento, ornamentada por tubérculos setíferos dispostos em duas fileiras paralelas do $2 \underline{0}$ ao $7 \underline{0}$ segmento. O $8 \underline{o}$ tergito, apresenta $1+1$ placas retangulares e $1+1$ placas ocupando toda porção lateral do $9 \underline{0}$ tergito. Não apresenta manchas conexivais.

2o estádio (Fig. 6) - Comprimento médio total de 6,4 \pm $0,18 \mathrm{~mm}$. Coloração castanho avermelhado claro apresentando cerdas implantadas em tubérculos dispostos em fileiras na região da fronte e de forma aleatória no vértex. Entre a largura da região pós-ocular e a da região anteocular a proporção média é de 1:2,6 e entre a largura da região ocular e a da região interocular é de 1:0,6. Os artículos antenais apresentam as seguintes proporções médias: 1:2,4:2,9:5,1. Proporções médias entre os segmentos do rostro: 1:3,1:1,2. Tórax coberto por cerdas inseridas em tubérculos dispostos aleatoriamente, com ângulos ântero-laterais claros. Mesonoto com uma faixa membranosa dupla. Manchas conexivais presentes. Apresenta uma área glabra central do $1^{\mathrm{O}}$ ao $5^{\mathrm{O}}$ tergitos no bordo posterior, $1+1$ áreas sublaterais do $1^{\mathrm{o}}$ ao $5 \underline{\mathrm{o}}$ tergitos e $1+1$ no bordo lateral do $1^{\mathrm{O}}$ ao $5 \mathrm{o}$ tergitos.

3o estádio (Fig. 7) - Comprimento médio total de 9,5 \pm $0,75 \mathrm{~mm}$. Coloração marrom-avermelhada, cerdas implan-

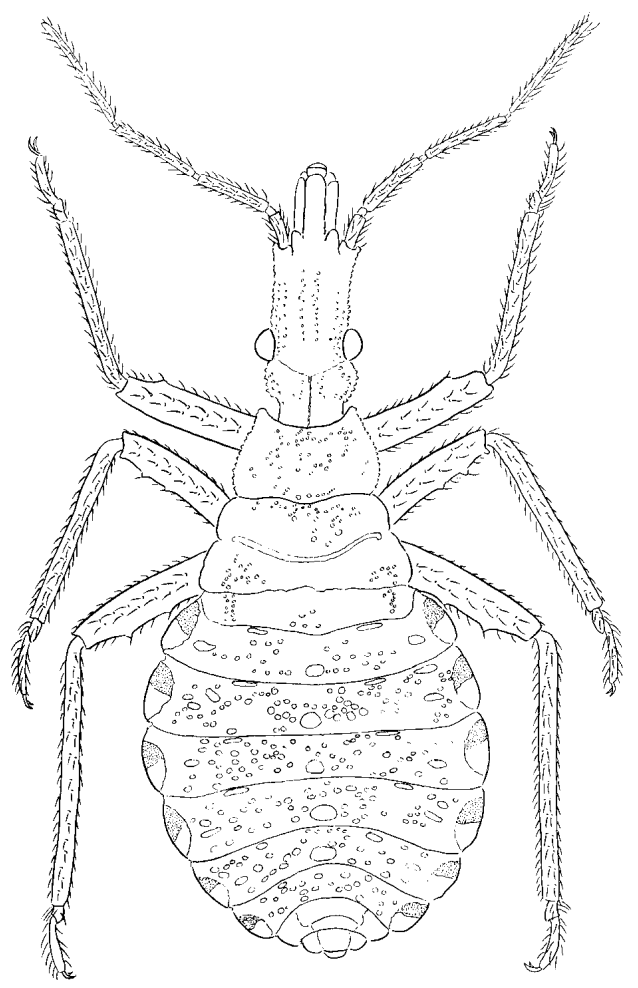

Fig. 6: Triatoma jurbergi Carcavallo, Galvão \& Lent, 1998 - Ninfa de 2 o estádio, vista dorsal

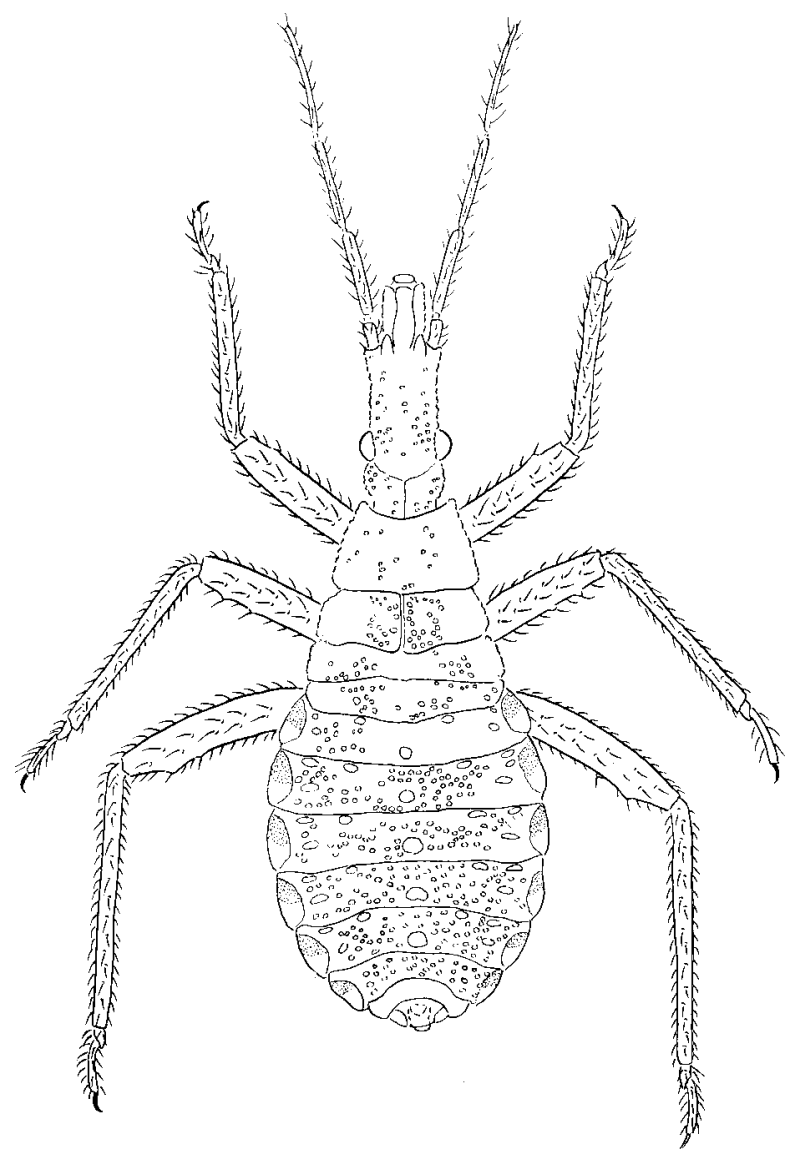

Fig. 7: Triatoma jurbergi Carcavallo, Galvão \& Lent, 1998 - Ninfa de 3 o estádio, vista dorsal

tadas em tubérculos setíferos na região anteocular até o pescoço, sendo duas fileiras centrais paralelas e jugas de forma triangular. Antenas de coloração negra nos três primeiros segmentos e a base do $4^{\mathrm{O}}$ segmento antenal. Abdome com $2+2$ áreas glabras no bordo lateral, $1+1$ subapical e uma central do 20 ao 5o tergitos. Entre a largura da região pós-ocular e a da região anteocular a proporção média é de 1:2,6 e entre a largura da região ocular e a da região interocular é de 1:0,7. Proporções médias entre os artículos antenais: 1:3,0:3,3:3,9. Rostro com as seguintes proporções médias: 1:3,2:1,2.

40 estádio (Fig. 8) - Comprimento médio total de 12, 8 $\pm 0,31 \mathrm{~mm}$. Coloração marrom-avermelhada, $1+1$ áreas glabras centrais na região do pronoto. Entre a largura da região pós-ocular e a da região anteocular a proporção média é de 1:2,8 e entre a largura da região ocular e a da região interocular é de 1:0,7. Artículos antenais com as seguintes proporções médias: $1: 3,4: 3,5: 3,4$. Proporções médias entre os segmentos do rostro: $1: 3,2: 1,2$. Tecas alares evidenciadas; o primeiro par atinge o bordo anterior do metatórax e o segundo atinge o $1^{\mathrm{o}}$ urotergito. Pernas de coloração marrom.

5ํe estádio (Fig. 9) - Comprimento médio total de $18 \pm$ $1 \mathrm{~mm}$. Coloração marrom-avermelhada. Cabeça contendo cerdas implantadas em tubérculos, localizados aleatoriamente nos bordos laterais da região anteocular e interocular, compondo o tegumento granuloso. Jugas com 


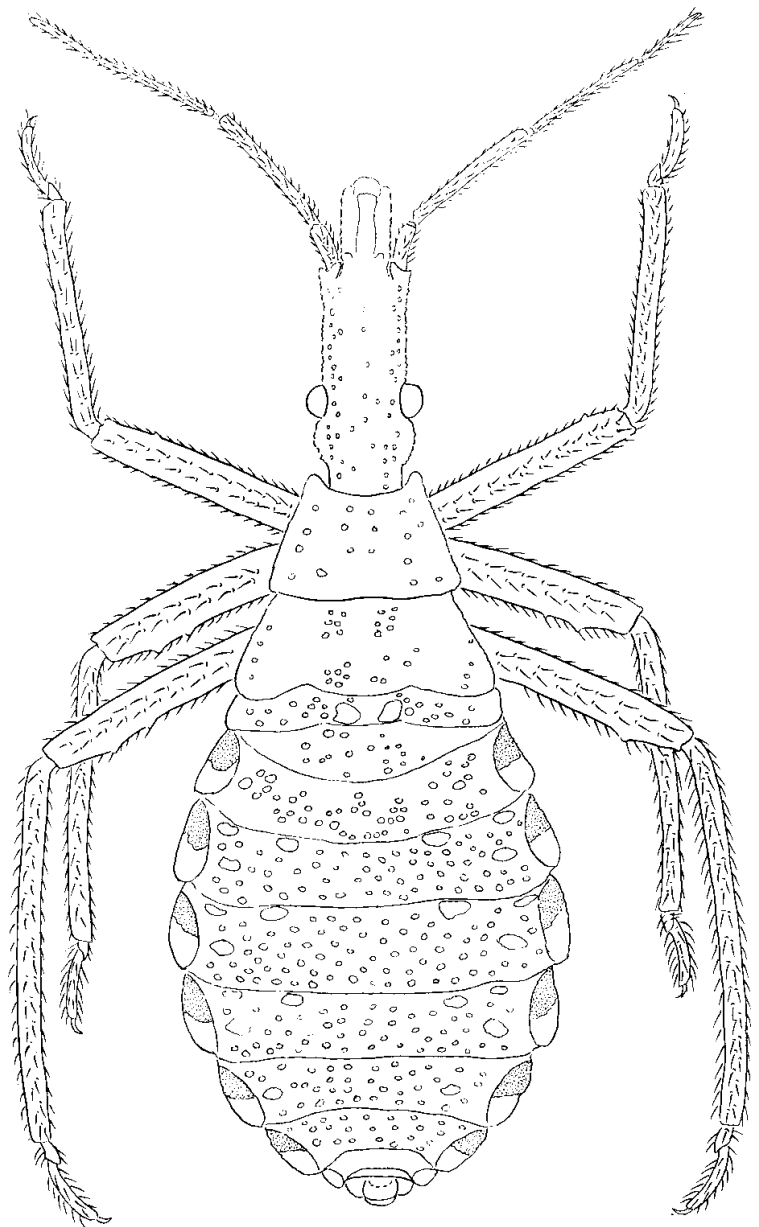

Fig. 8: Triatoma jurbergi Carcavallo, Galvão \& Lent, 1998 - Ninfa de 4을 estádio, vista dorsal

formato triangular, com $1+1$ protuberâncias dorsais no ponto de surgimento dos ocelos. Olhos compostos negros, constituídos por vários omatídeos justapostos. Os três primeiros segmentos antenais e a base do quarto são de coloração negra. Tórax, marrom-avermelhado, com os ângulos ântero-laterais e humerais mais claros, $1+1$ áreas de aspecto reniforme no mesotórax. Tecas alares atingem o bordo inferior do segundo segmento abdominal. $\mathrm{O}$ abdome mostra manchas conexivais contendo uma região mais escura. Entre a largura da região pós-ocular e da região anteocular a proporção média é de 1:2,7 e entre a largura da região ocular e da região interocular é de 1:0,6. Artículos antenais com proporções médias de 1:3,9:3,0:2,8. Os segmentos do rostro apresentam as proporções médias de $1: 3,6: 1,2$.

A análise ultra-estrutural do rostro em sua face dorsal mostra estruturas peculiares como, por exemplo, $1+1$ fendas laterais próximas ao ápice do rostro em todos os estádios (Fig. 10). Na face ventral a placa apical, localizada no extremo ápice do rostro, apresenta-se delimitada por três $(3+3)$ sensilas, que vão aumentando de tamanho gradativamente da base para o ápice (Fig. 10). O tubérculo antenífero e os dois primeiros segmentos antenais apresentam-se revestidos por um tegumento reticular. Na base

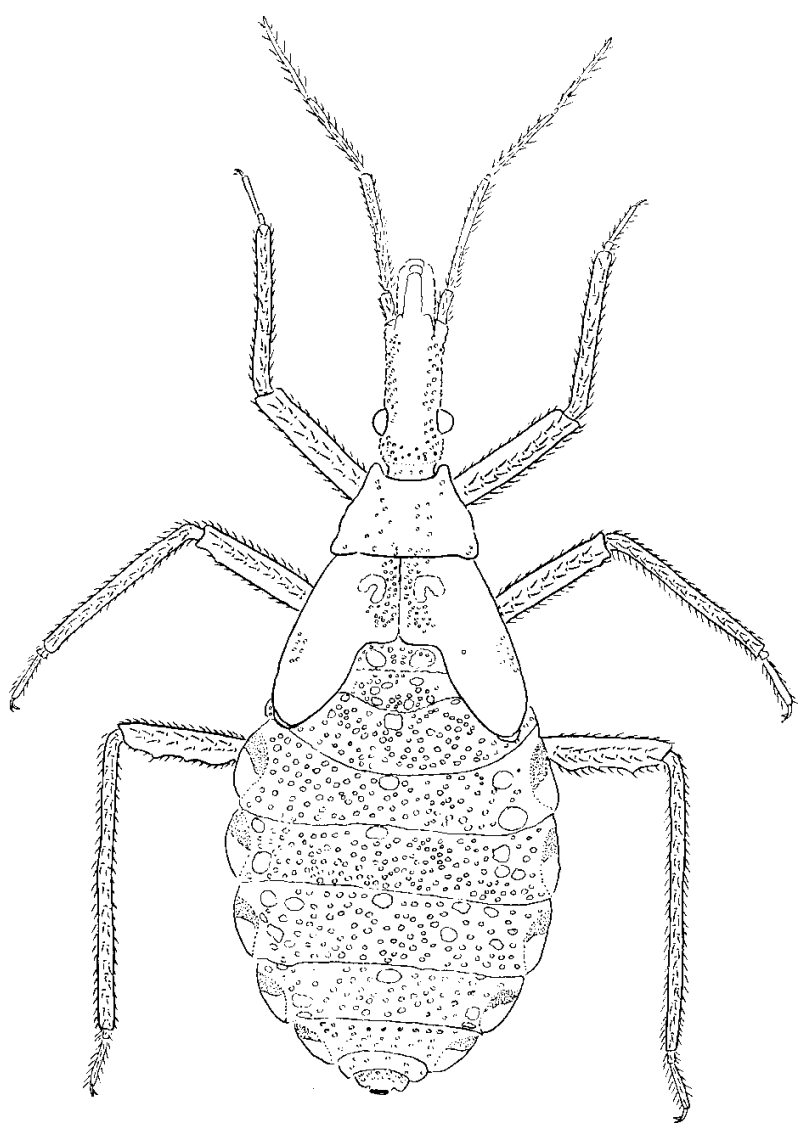

Fig. 9: Triatoma jurbergi Carcavallo, Galvão \& Lent, 1998 - Ninfa de 5 o estádio, vista dorsal

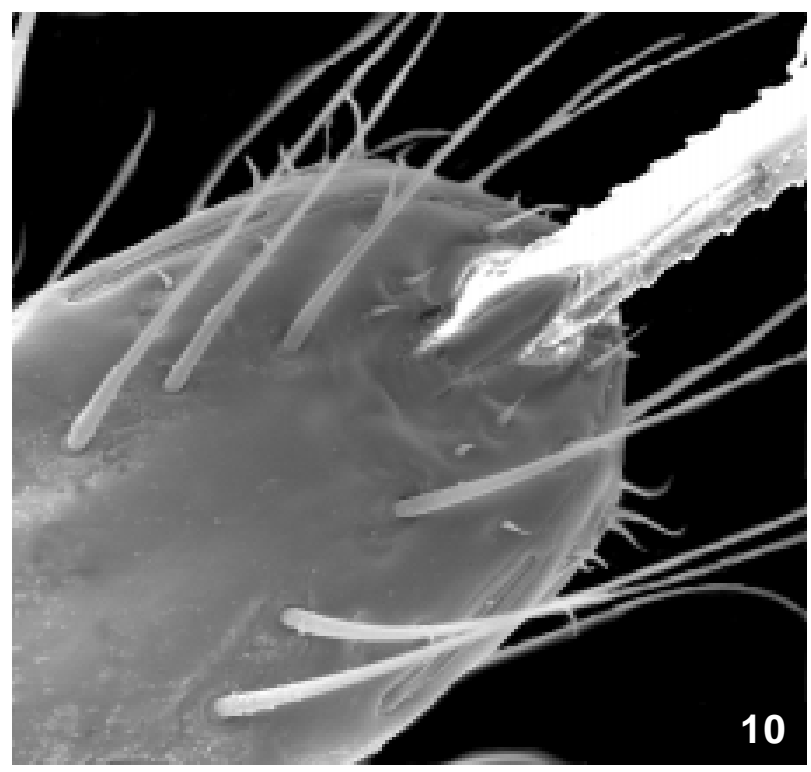

Fig. 10: Triatoma jurbergi Carcavallo, Galvão \& Lent, 1998 - Ninfa de 5o estádio, vista ventral do ápice do rostro em MEV apresentando fendas laterais (450X) 

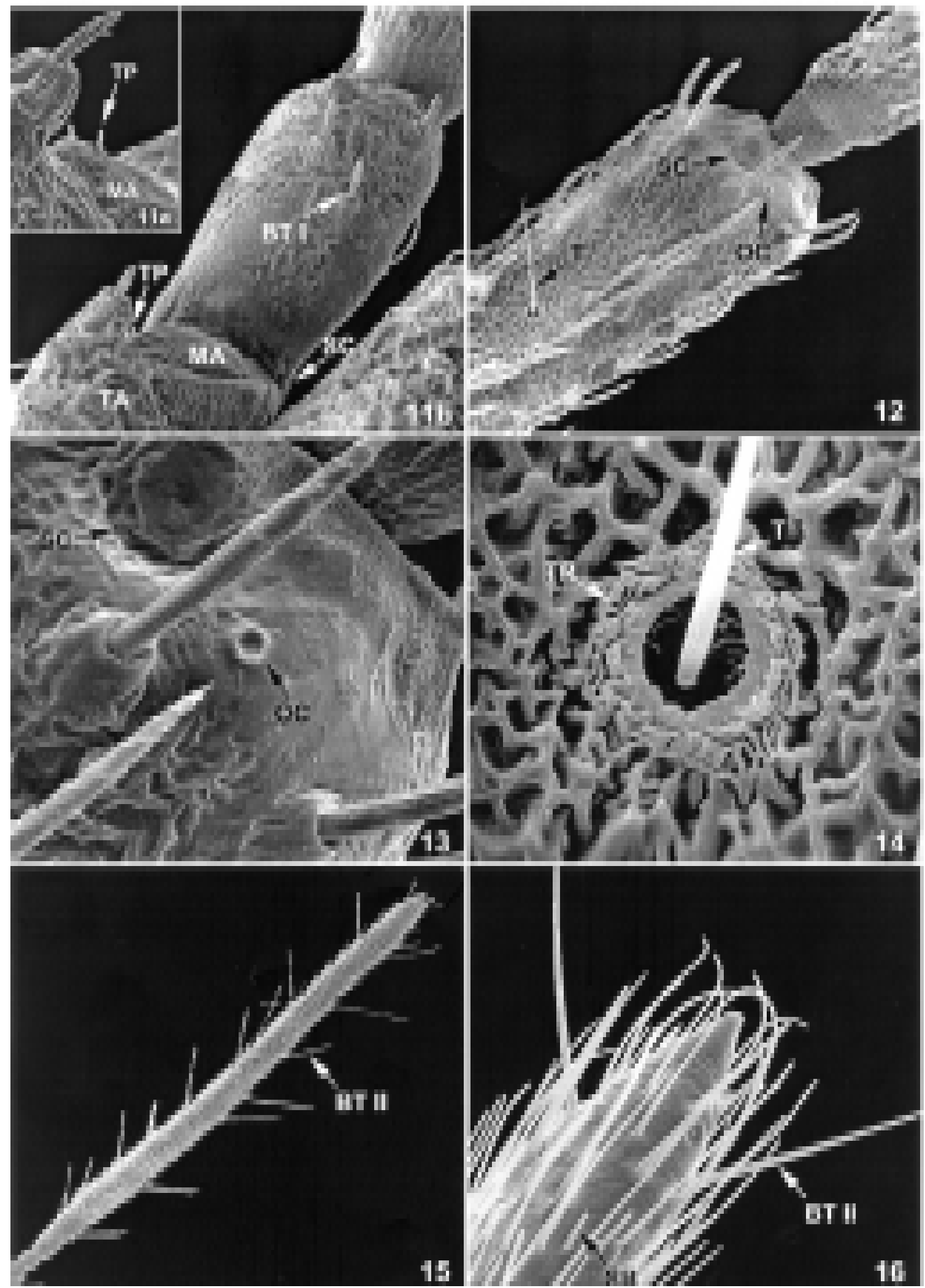

Triatoma jurbergi Carcavallo, Galvão \& Lent, 1998 - Fig. 11a,b: ninfa de 10 estádio, vista dorsal do 1ㅇ segmento antenal por MEV. TB: tubérculo antenífero; TP: "taperd hair"; MA: membrana articular; BTI: bristles tipo I; SC: sensila campaniforme (250X). Fig. 12: ninfa de $3^{\circ}$ estádio, vista dorsal do $2^{\mathrm{o}}$ segmento antenal por MEV. T: tricobótria; OC: "órgão cova”; SC: sensila campaniforme (240X). Fig. 13: detalhe da sensila campaniforme (SC) e do "órgão cova" no ápice do $2^{2}$ segmento antenal (975X). Fig. 14: detalhe da insersão da tricobótria (T) no segundo segmento antenal e do tecido reticular (TR) (250X). Fig. 15: ninfa de 1을 estádio, vista dorsal do extremo ápice do 4o segmento antenal por MEV. BT II: bristles tipo II, SB: sensilla basicônica (60X). Fig. 16: detalhe do ápice do 4ํㅜ segmento antenal, mostrando a sensila basicônica (SB) e bristles tipo II (BT II) (725X) 
do tubérculo o número de cerdas aumenta com a evolução dos estádios ninfais. A membrana articulatória, localizada entre o tubérculo antenífero e o $1 \stackrel{\mathrm{O}}{\text { segmento }}$ (escapo), mostrou-se ricamente granulosa e com dois "tapered hair" inseridos lateralmente na base do $1^{\underline{O}}$ segmento (Fig. 11a). Neste segmento, foram encontradas sensilas bristles tipo I e na região interna basal, a sensila campaniforme (Fig.11b). Na face dorsal do $2 \mathrm{o}$ segmento antenal de todos os estádios, observa-se uma tricobótria única (Fig. 12). Esta sensila encontra-se inserida numa modificação do tecido reticular que reveste todo o segmento (Fig. 13). Neste segmento, nas ninfas de $3 \underline{0}$ estádio, observa-se uma estrutura circular parecendo tratar-se do "órgão cova" (Fig. 14). O 4o segmento antenal apresenta o extremo ápice afilado no $1^{\circ}$ estádio e arredondado nos estádios seguintes; observam-se ainda, sensilas dos tipos bristles tipo II e sensila basicônica (Figs. 15 e 16).

\section{DISCUSSÃO}

A importância do conhecimento dos ovos dos triatomíneos foi ressaltada por Pinto (1924), quando foram descritos os ovos de Triatoma brasiliensis Neiva, 1911 diferenciando-os de outras espécies de "barbeiros" do Brasil, pertencentes ao gênero Triatoma. Os primeiros caracteres utilizados para o estudo dos ovos, foram baseados nas características macroscópicas quanto ao tamanho, à forma, à coloração, ao tipo de exocório e à fixação, dentre outros aspectos (Galliard 1935). Barata (1981), através de $\mathrm{MO}$ e MEV, demonstrou a possibilidade da utilização de diversas estruturas e ornamentações do ovo como parâmetros na diagnose das espécies, elaborando uma chave para identificação de dez espécies do gênero Rhodnius, baseada em características do corpo e do opérculo dos ovos. Mais recentemente, o mesmo autor observou aspectos da morfologia externa, da mensuração e do exocório de ovos em nove dos 17 gêneros conhecidos de Triatominae (Barata 1998). No presente trabalho, através de MEV, foi descrita a superfície dos ovos de $T$. jurbergi observando-se os caracteres no exocório, que apresentam as células do opérculo e do corpo pentagonais e hexagonais e, adicionalmente, o estudo morfométrico descrevendo o comprimento e a largura dos ovos. Comparativamente, espécies pertencentes ao mesmo complexo, quando observadas por MO, apresentam características macroscópicas no exocório capazes de distinguir as espécies. Em T. guazu, o opérculo e o corpo são formados por células poligonais justapostas com pequenas perfurações distribuídas aleatoriamente (Silva et al. 2000), enquanto $T$. jurbergi apresenta o opérculo ornamentado por pequenas fraturas e o corpo, além de pequenas fraturas, pontuações distribuídas aleatoriamente. Em $T$. matogrossensis, o exocório é ornamentado por um sistema de linhas irregulares e curvadas que se comunicam entre si podendo, em alguns polígonos, formar figuras fechadas (Jurberg \& Vogel 1994). Com relação ao comprimento dos ovos das três espécies, o ovo de T. jurbergi é maior que o de T. guazu e de T. matogrossensis. As diferenças cromáticas entre estas espécies em todos os estádios têm sido observadas (Jurberg \& Vogel 1994, Silva et al. 2000, dados descritos no presente artigo). Atualmente, diversos autores vêm buscando novos parâmetros que, associados aos apresentados por Lent e Wygodzinsky (1979), permitam avançar e tentar elaborar uma chave de identificação específica, assim como analisar comparativamente as estruturas identificadas por MEV, que possam ser pareadas entre as espécies afins e entre os complexos. No rostro das ninfas de $1^{\circ}$ a $5 \underline{0}$ estádio foram observadas em $T$. jurbergi, $1+1$ fendas laterais próximas ao ápice do rostro. Estruturas estas, descritas também em $T$. guazu (Silva 2000) e semelhantes às encontradas por Lent e Wygodzinsky (1979) exclusivamente no gênero Dipetalogaster. Da Rosa et al. (1999) analisaram por MEV estruturas morfológicas da cabeça de ninfas de $T$. circummaculata e de T. rubrovaria, encontrando diferenças na calosidade pós-ocular, no número de omatídeos, nos três segmentos do rostro e entre os segmentos antenais. A análise ultra-estrutural da antena de $T$. jurbergi, aqui descrita, identifica o tubérculo antenífero revestido por um tegumento reticular, que se apresenta também nos dois primeiros segmentos antenais. Na base do tubérculo, o número de cerdas aumenta com a evolução dos estádios ninfais. A membrana articulatória, localizada entre o tubérculo antenífero e o $1^{10}$ segmento (escapo), mostrou-se ricamente granulosa e com dois "tapered hair" inseridos lateralmente na base deste segmento, à semelhança de T. guazu (Silva 2000). Catalá e Schofield (1994) identificaram doze tipos de sensilas nas antenas dos adultos de dez espécies do gênero Rhodnius. No $1^{\underline{o}}$ segmento da antena de $T$. jurbergi foram encontradas sensilas bristles tipo I e na região interna basal, a sensila campaniforme. No $2^{\mathrm{o}}$ segmento encontramos uma única sensila, a tricobótria em todos os estádios, a qual apresenta característica diferente daquela de T. guazu (Silva 2000), quando se observa que no $1^{\circ}$ estádio esta sensila tem metade do seu comprimento atingindo o 3 o segmento antenal, diferentemente de T. jurbergi, cuja tricobótria no 1 o estádio apresenta uma pequena porcão atingindo o $3^{\circ}$ segmento antenal. Catalá (1994) e Catalá e Schofield (1994) identificaram o "órgão cova", como um receptor sensorial, de função ainda desconhecida, que pode ser observado no $2^{\mathrm{O}}$ segmento antenal dos adultos de triatomíneos. Em $T$. jurbergi foi observado, pela primeira vez, que somente as ninfas de $3^{\mathrm{o}}$ estádio possuem no $2^{\mathrm{O}}$ segmento antenal uma única estrutura circular, diferindo de T. guazu que apresenta duas estruturas circulares no mesmo estádio ninfal e segmento antenal (Silva 2000), a sua localização e estrutura morfológica sugerem tratar-se do "órgão cova".

Os resultados apresentados no presente artigo constituem o primeiro estudo morfológico ultra-estrutural dos ovos e dos cinco estádios ninfais de T. jurbergi que deverão fornecer uma contribuição importante na taxonomia dos triatomíneos.

Estudos morfológicos e bioquímicos das demais espécies pertencentes ao "complexo oliveirai" estão em curso.

\section{AGRADECIMENTOS}

À técnica Vanda Cunha pela fotografia do habitat silvestre de Triatoma jurbergi e pelo fornecimento do material analisado e a Bruno Ávila do Laboratório de Ultra-estrutura Celular, Departamento de Ultra-estrutura e Biologia Celular pelo processamento das imagens e arte final do trabalho. 


\section{REFERÊNCIAS}

Barata JMS 1981. Aspectos morfológicos de ovos de triatomíneos. II - Características macroscópicas e exocoriais de dez espécies do gênero Rhodnius Stal, 1859 (HemipteraReduviidae). Rev Saúde Púb São Paulo 15: 490-542.

Barata JMS 1998. Macroscopic and exocorial structures of Triatominae eggs (Hemiptera, Reduviidae). Estruturas macroscópicas e exocoriais de ovos de Triatominae (Hempitera, Reduviidae). In RU Carcavallo, I GalíndezGirón, J Jurberg, H Lent (orgs.), Atlas of Chagas Disease Vectors in the Americas. Atlas dos Vetores da Doença de Chagas nas Américas, Vol. II, Fiocruz, Rio de Janeiro, p. 409-448.

Carcavallo RU, Galvão C, Lent H 1998. Triatoma jurbergi sp.n. do Norte do Estado do Mato Grosso, Brasil (Hemiptera, Reduviidae, Triatominae) com uma atualização das sinonímias e outros táxons. Mem Inst Oswaldo Cruz 93: 459-464.

Carcavallo RU, Justus NS, Martínez AM 1978. Descripción del las ninfas de II, III y IV estadio de Alberprosenia goyovargasi Martinéz \& Carcavallo, 1977 (Hemiptera, Reduviidae, Triatominae). Observaciones com microscopía eletrónica de barrido. Bol Dir Malariol San Amb 18: 132131.

Carcavalo RU, Otero MA, Martinéz A, Tom RJ 1975. Notas sobre la biología, ecología y distribución geográfica del Psammolestes arthuri (Pinto), 1926 (Hemiptera, Reduviidae). Descripción de los estadios preimagales. Bol Dir Malariol San Amb 15: 231-239.

Catalá S 1997a. Antennal sensilla of Triatominae (Hemiptera, Reduviidae): a comparative study of five genera. Int J Insect Morphol Embryol 26: 67-73

Catalá S 1997b. Antennae and rostrum. Antenas e rostro. In RU Carcavallo, I Galíndez-Girón, J Jurberg, H Lent (orgs.), Atlas of Chagas Disease Vectors in the Americas. Atlas dos Vetores da Doença de Chagas nas Américas, Vol. I, Fiocruz, Rio de Janeiro, p.74-83.

Catalá S 1994. The cave organ of Triatominae bugs. Mem Inst Oswaldo Cruz 89: 275-277.

Catalá S, Schofield CJ 1994. Antennal sensila of Rhodnius. J Morphol 219: 193-203.

Costa J, Jurberg J, Barth MO 1991. Estudos morfológicos de Cavernicola lenti Barrett \& Arias, 1985 (Hemiptera, Reduviidae, Triatominae). Mem Inst Oswaldo Cruz 86: 247-263.

Da Rosa JA, Barata, JMS, Ciliense M, Belda Neto FM 1999. Head morphology of $1^{\text {st }}$ and $5^{\text {th }}$ instar nynphs of Triatoma circummaculata and Triatoma rubrovaria (Hemiptera, Reduviidae). Int J Insect Morphol Embryol 28: 363-375.

Galíndez-Girón I, Rocha DS, Lent H, Carcavallo RU, Jurberg J, Galvão C, Santos HB, Martínez A, Barata JMS, Da Rosa JA 1998. Nynphal Stages. Estádios Ninfais. In RU Carcavallo, I Galíndez-Girón, J Jurberg, H Lent (orgs.), Atlas of Chagas Disease Vectors in the Americas. Atlas dos Vetores da Doença de Chagas nas Américas, Vol. II, Fiocruz, Rio de Janeiro, p. 449-513.

Galliard H 1935 Recherches sur les réduvidés hématophagaes Rhodnius et Triatoma. V. Morphologie de l'oeuf des triatomes. Ann Parasit Hum Comp 13: 511-527.

Gonçalves TCM, Jurberg J, Costa JM, Souza W 1985. Estudo morfológico comparativo de ovos e ninfas de Triatoma maculata (Erichson,1848) e Triatoma pseudomaculata Correa \& Espínola, 1964 (Hemiptera, Reduviidae, Triatominae). Mem Inst Oswaldo Cruz 80: 276-280.

Jiménez OH, Fuentes O 1981. Triatoma flavida (Hemiptera: Reduviidae). I. Estudo biométrico de larvas. Rev Cubana
Med Trop 33: 195-200.

Jurberg J, Campos P 1995. Morfologia de huevos y ninfas de Triatoma vitticeps (Stal,1859) (Hemiptera, Reduviidae). Entomol Vect 2: 9-22.

Jurberg J, Vogel M 1994. Morfologia de huevos y ninfas de Triatoma matogrossensis Leite \& Barbosa, 1953 (Hemiptera: Reduviidae). Entomol Vect 1: 167-177.

Jurberg J, Galvão C, Barth OM 1990. Estudo morfológico de ovos e ninfas de Triatoma nitida Usinger,1939 (Hemiptera, Reduviidae, Triaominae). Rev Brasil Biol 5: 365-372.

Jurberg J, Gonçalves TCM, Costa JM, Souza W 1986. Contribuição ao estudo morfológico de ovos e ninfas de Triatoma brasiliensis Neiva,1911 (Hemiptera, Reduviidae, Triatominae). Mem Inst Oswaldo Cruz 81: 111-120.

Jurberg J, Lima MG, Rocha DS, Carcavallo RU, Galvão C 1998. Descrição dos ovos e ninfas de Triatoma melanosoma Martínez, Olmedo \& Carcavallo, 1987 (Hemiptera, Reduviidae). Entomol Vect 5: 67-84.

Lent H, Wygodzisnky P 1979. Revision of the Triatominae (Hemiptera - Reduviidae) and their significance as vectors of Chagas' disease. Bull Amer Mus Natur Hist 163: 123520.

Lorosa ES, Andrade RE, Vinhaes MC, Figueredo J, Jurberg J 2001. Determinação das fontes alimentares e da infecção natural do Triatoma jurbergi (Carcavallo, Galvão, Lenti, 1998) e Triatoma williami (Galvão, Souza e Lima,1965) capturado no Estado do Mato Grosso, Brasil. (sic.) Rev Soc Bras Med Trop 34: 125.

Mascarenhas BM 1987. Descrição dos estádios imaturos de Rhodnius brethesi Matta, 1919 (Hemiptera, Reduviidae). Bol Mus Par Emilio Goeldi S Zool 3: 183-194.

Mc Iver S 1975. Structure of cuticular mechanoreceptors of arthropods. Ann Rev Entomol 20: 381-397.

Mc Iver S, Siemicki R 1984. Fine structure of antennal mechanosensilla of adult Rhodnius prolixus Stal (Hemiptera, Reduviidae). J Morphol 180: 19-28.

Mc Iver S, Siemicki R 1985. Fine structure of antennal putative thermohygrosensilla of adult Rhodnius prolixus Stal (Hemiptera - Reduviidae). J Morphol 183: 15-23.

Pinto C 1924. Biologia do Triatoma brasiliensis Neiva. Sciência Médica 2: 541-543.

Rocha DS, Jurberg J, Galvão C 1996. Descrição dos ovos e ninfas de Triatoma lecticularia (Stal, 1859) (Hemiptera, Reduviidae, Triatominae). Entomol Vect 3: 123-135.

Silva MBA 2000. Morfologia e Morfometria de Triatoma guazu Lent \& Wygodzinsky, 1979 e Triatoma jurbergi Carcavallo, Galvão \& Lent, 1998, Através de Microscopia Óptica e Eletrônica de Varredura (Hemiptera, Reduviidae), MSc Thesis. Fundação Oswaldo Cruz, Rio de Janeiro, 93 pp.

Silva MBA, Jurberg J, Cunha V, Carcavallo RU, Galvão C 1998. Some aspects of the biology of Triatoma jurbergi Carcavallo, Galvão \& Lent, 1998 (Hemiptera, Reduviidae, Triatominae), under laboratory conditions. Mem Inst Oswaldo Cruz 93 (Suppl. II): 345.

Silva MBA, Jurberg J, Galvão C, Carcavallo RU 2000. Estudo morfológico e morfométrico de ovos e ninfas de Triatoma guazu Lent \& Wygodzinsky, 1979 (Hemiptera, Reduviidae, Triatominae) vistos por microscopia óptica e eletrônica de varredura. Entomol Vect 7: 311-334.

Silva MBA, Rocha DS, Galvão C, Cunha V, Carcavallo RU, Jurberg J 1999. Weigth reduction of each instar of Triatoma jurbergi Carcavallo, Galvão \& Lent, 1998 (Hemiptera, Reduviidae) permitted only one bloodmeal. Mem Inst Oswaldo Cruz 94 (Suppl. II): 249.

Zacharuk RY 1980. Ultrastructure and function of insect chemosensilla. Ann Rev Entomol 25: 27-47. 